NASA/CR-2005-213354

\title{
Design Considerations for High Temperature Power Inductors
}

Janis M. Niedra

QSS Group, Inc., Cleveland, Ohio 
Since its founding, NASA has been dedicated to the advancement of aeronautics and space science. The NASA Scientific and Technical Information (STI) Program Office plays a key part in helping NASA maintain this important role.

The NASA STI Program Office is operated by Langley Research Center, the Lead Center for NASA's scientific and technical information. The NASA STI Program Office provides access to the NASA STI Database, the largest collection of aeronautical and space science STI in the world. The Program Office is also NASA's institutional mechanism for disseminating the results of its research and development activities. These results are published by NASA in the NASA STI Report Series, which includes the following report types:

- TECHNICAL PUBLICATION. Reports of completed research or a major significant phase of research that present the results of NASA programs and include extensive data or theoretical analysis. Includes compilations of significant scientific and technical data and information deemed to be of continuing reference value. NASA's counterpart of peerreviewed formal professional papers but has less stringent limitations on manuscript length and extent of graphic presentations.

- TECHNICAL MEMORANDUM. Scientific and technical findings that are preliminary or of specialized interest, e.g., quick release reports, working papers, and bibliographies that contain minimal annotation. Does not contain extensive analysis.

- CONTRACTOR REPORT. Scientific and technical findings by NASA-sponsored contractors and grantees.
- CONFERENCE PUBLICATION. Collected papers from scientific and technical conferences, symposia, seminars, or other meetings sponsored or cosponsored by NASA.

- SPECIAL PUBLICATION. Scientific, technical, or historical information from NASA programs, projects, and missions, often concerned with subjects having substantial public interest.

- TECHNICAL TRANSLATION. Englishlanguage translations of foreign scientific and technical material pertinent to NASA's mission.

Specialized services that complement the STI Program Office's diverse offerings include creating custom thesauri, building customized databases, organizing and publishing research results ... even providing videos.

For more information about the NASA STI Program Office, see the following:

- Access the NASA STI Program Home Page at http://www.sti.nasa.gov

- E-mail your question via the Internet to help@sti.nasa.gov

- Fax your question to the NASA Access Help Desk at 301-621-0134

- Telephone the NASA Access Help Desk at 301-621-0390

- Write to:

NASA Access Help Desk

NASA Center for AeroSpace Information 7121 Standard Drive

Hanover, MD 21076 
NASA/CR-2005-213354

AIAA-2004-5748

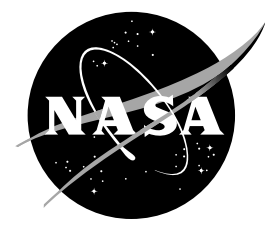

\section{Design Considerations for High Temperature Power Inductors}

Janis M. Niedra

QSS Group, Inc., Cleveland, Ohio

Prepared for the

Second International Energy Conversion Engineering Conference

sponsored by the American Institute of Aeronautics and Astronautics

Providence, Rhode Island, August 16-19, 2004

Prepared under Contract NAS3-00145

National Aeronautics and

Space Administration

Glenn Research Center 


\section{Acknowledgments}

This work was sponsored by the NASA Glenn Research Center under contract NAS3-98008 and NAS3-00145, with G.E. Schwarze as the Project Manager.

Trade names or manufacturers' names are used in this report for identification only. This usage does not constitute an official endorsement, either expressed or implied, by the National Aeronautics and Space Administration.

Available from

NASA Center for Aerospace Information 7121 Standard Drive

Hanover, MD 21076
National Technical Information Service 5285 Port Royal Road Springfield, VA 22100 


\title{
Design Considerations for High Temperature Power Inductors
}

\author{
Janis M. Niedra, \\ QSS Group, Inc., \\ Cleveland, Ohio 44135
}

\begin{abstract}
A uniform B-field approximation model is used to develop design formulas for single-layer wound, toroidal core, ac power inductors that must handle a specified current. Such a geometry is well suited for high temperature, high frequency inductors, where removal of heat from the core becomes critical. Explicit expressions are derived for core radii, core and winding volumes, winding turns and core permeability as functions of a dimensional scaling ratio (S). A limit on the maximum allowed core B-field leads to the result that the minimum core volume is proportional to the permeability, which has a lower bound. Plots versus $S$ are provided for a specific case, to show that good designs can be picked in the overlap regions around the minima in mass and overall size, where the mass and size are relatively flat. Data to $250 \mathrm{C}$ are presented for an MPP core based inductor to show that a quasi-linear, high temperature inductor can be constructed with available materials. A similar development is applied to a toroidal air-core geometry, showing that for the same ratings, such an inductor is considerably bigger and more massive, at least in the single-layer version.
\end{abstract}

\section{Introduction}

This paper outlines the fundamental considerations for the design of toroidal ac power inductors that are subject to currents sufficiently high to cause the onset of magnetic saturation. These design considerations are especially important for inductors operating at high temperatures, when the saturation flux density is reduced and cooling problems become more severe. Within the last 10 years, there has been an increase in commercially available soft magnetic cores, based on transverse magnetically annealed metallic glass tapes. Such cores have quite linear B-H characteristics and saturate sharply at flux densities as high as $1 \mathrm{~T}$. However, without permeability control, the high permeabilities of metallic glass and glass-derived materials make for cores that are impractical in high current applications. Further, these materials are restricted to temperatures below about $150 \mathrm{C}$. This pares down the present choices to rather few materials of the "distributed gap" (powder) type, such as MPP (Moly Permalloy Powder) or powdered iron, but insulated particle, nanocomposite magnetic materials may be a future option.

Here the first-cut approach to design and core material selection considers three criteria:

1. Ability to handle a specified peak current $\mathrm{I}_{\mathrm{p}, \max }$,

2. A specified inductance L,

3. Adaptability to high temperature ( $\geq 200 \mathrm{C})$ operation.

These considerations relate to the magnetic material, wire gauge and winding distribution. One may also place restrictions on the variation of $L$ with the peak current $I_{p}$, on allowable core and winding losses, etc. However, such materials dependent considerations are difficult to handle in a simple way and therefore will be avoided.

In accordance with simplicity, the variation of the B-field over the core cross-section will be ignored here. Strictly speaking, formulas that involve the mean path $(\bar{\ell})$ concept for a core, e.g., Eqs. (1) and (2) below, are not accurate for "fat" toroids. However, simple modeling yields explicit formulas that uncover the action of various input parameters, whereas the more precise formulas lead to machine computation that obscures the basic influences. The author has done such (unpublished) numerical computations that evaluate mass and include also the core loss by power-law formulas.

\section{A. Magnetic Non-saturation Condition}

\section{Analysis}

The requirements 1 . and 2. above turn out to be quite restrictive on core volume, because with the exception of vacuum, all core materials are subject to magnetic saturation. In particular, the peak flux density $\mathrm{B}_{\mathrm{p}}$ must be limited 
to some value $\mathrm{B}_{\mathrm{p}, \max } \leq \mathrm{B}_{\mathrm{sat}}$, in order to obtain an acceptably linear inductor. Thus for the MPP material, strong nonlinearity is to be expected for $\mathrm{B}_{\mathrm{p}}$ exceeding $\sim 0.6 \mathrm{~T}$, which is still well below its $\mathrm{B}_{\text {sat }}$.

The restriction involving core volume can be set down in essentially one line from energy considerations, or derived in a more tedious way, as follows. A toroidal core having a cross-section $\mathrm{A}$ and a mean circumference $\bar{\ell}$, is assumed to be characterized by a magnetic permeability $\mu=\mu_{\mathrm{r}} \mu_{0}$. Its volume is then $v_{\mathrm{c}}=\bar{\ell} \mathrm{A}$. For a peak current $\mathrm{I}_{\mathrm{p}}$ flowing through an $\mathrm{N}$-turn winding, the peak flux density is

$$
\mathrm{B}_{\mathrm{p}}=\frac{\mu \mathrm{N}}{\bar{\ell}} \mathrm{I}_{\mathrm{p}}
$$

And $\mathrm{N}$ is related to $\mathrm{L}$ by

$$
\mathrm{L}=\mu \frac{\mathrm{A}}{\bar{\ell}} \mathrm{N}^{2}=\mathrm{v}_{\mathrm{c}} \mu(\mathrm{N} / \bar{\ell})^{2}=\mu \frac{\mathrm{A}^{2}}{\mathrm{v}_{\mathrm{c}}} \mathrm{N}^{2}
$$

After a little algebra to eliminate $\mathrm{N}$, the requirement that $\mathrm{B}_{\mathrm{p}} \leq \mathrm{B}_{\mathrm{p}, \max }$ can be put into the form

$$
\mathrm{v}_{\mathrm{c}} \geq \mu \mathrm{L}\left(\mathrm{I}_{\mathrm{p}, \max } / \mathrm{B}_{\mathrm{p}, \max }\right)^{2}
$$

This result is the same as saying that the peak inductive energy storage $\frac{1}{2} \mathrm{~L} \mathrm{I}_{\mathrm{p} \text {,max }}^{2}$ cannot exceed the maximum magnetic energy storage capability $\frac{1}{2 \mu} \mathrm{B}_{\mathrm{p}, \max }^{2} v_{\mathrm{c}}$ of the core material. Thus for a given core material (specified $\mu_{\mathrm{r}}$ and $\mathrm{B}_{\mathrm{p}, \max }$ ), the quantity

$$
\mathrm{v}_{\mathrm{c}, \min } \equiv \mu \mathrm{L}\left(\mathrm{I}_{\mathrm{p}, \max } / \mathrm{B}_{\mathrm{p}, \max }\right)^{2}
$$

is the minimum allowed core volume. Conversely, if $v_{c} \geq v_{c}$, min, then $B_{p} \leq B_{p \text {, max }}$ will be satisfied. For design at maximum ratings, all above inequalities of course become equalities.

The result that the minimum core volume needed for a given L increases directly with permeability may seem counter intuitive. However, this is a consequence of the material limit on the maximum B-field, together with the fact that for a given B-field, a higher permeability material stores less magnetic energy.

\section{B. Winding Size}

The conclusion from Eq. (4) that the core volume can be reduced by choosing a lower $\mu$ material is true only to a point, because the window area of the core must accommodate a certain size of winding. The winding size is determined not only by the required number of turns, but also by the wire cross-section and the winding distribution. The wire size and turns distribution is greatly influenced by temperature and heat removal considerations. A high frequency inductor required to tolerate a hot environment may need a single layer winding to both facilitate heat removal from the core and to avoid excessive capacitive effects. Once wire size and turns distribution are specified, the remaining degrees of freedom are restricted to one or two and can be picked to be core dimensional scaling ratios. For minimum core volume designs using a material type characterized by a fixed $\mathrm{B}_{\mathrm{p} \text {, max }}$, variation of such ratios will also vary the required permeability, as well as the core-to-winding mass and power loss ratios, with a tradeoff between total mass and total losses.

Somewhat trivial bounds on the number of turns per unit of core mean circumference $(\mathrm{N} / \bar{\ell})$ can be put in a form independent of the details of core shape, which however illustrates the dependence on the basic input parameters. An upper bound follows from 


$$
\mathrm{B}_{\mathrm{p}, \max } \geq \frac{\mu \mathrm{N}}{\bar{\ell}} \mathrm{I}_{\mathrm{p}, \max }
$$

which is just the condition $\mathrm{B}_{\mathrm{p}} \leq \mathrm{B}_{\mathrm{p}}$, max applied to Eq. (1). Hence

$$
\mathrm{N} / \bar{\ell} \leq \frac{\mathrm{B}_{\mathrm{p}, \max }}{\mu \mathrm{I}_{\mathrm{p}, \max }}
$$

A form from Eq. (2) can be used together with Eq. (3) to show that

$$
\mathrm{N} / \bar{\ell} \geq\left(\frac{\mathrm{L}}{\mathrm{U}}\right)\left(\frac{\mathrm{I}_{\mathrm{p}, \max }}{\mathrm{B}_{\mathrm{p}, \max }}\right) .
$$

The combined result then is

$$
\left(\frac{\mathrm{L}}{\mathrm{v}}\right)\left(\frac{\mathrm{I}_{\mathrm{p}, \max }}{\mathrm{B}_{\mathrm{p}, \max }}\right) \leq \mathrm{N} / \bar{\ell}=\left(\frac{\mathrm{L}}{\mu \mathrm{v}}\right)^{1 / 2} \leq \frac{\mathrm{B}_{\mathrm{p}, \max }}{\mu \mathrm{I}_{\mathrm{p}, \max }} .
$$

The inequalities in Eq. (6) become strictly equalities if and only if the design is at maximum ratings (i.e., $v=v_{\min }$ ).

\section{Single-Layer Windings and Minimum Mass}

Here we shall treat the somewhat involved problem of minimizing mass or size in the case of a single-layer winding on a quasi-linear magnetic core material. Such a winding is suitable for high currents at high temperatures. The winding has a wire center-to-center spacing $\delta$ around the periphery of the window area of a core in the shape of a torus. A diagram of the geometry is provided in Fig. 1. Except for the magnetic material, the same geometry is used for the air core $\left(\mu_{\mathrm{r}}=1\right)$ in Appendix A and hence certain formulas developed there can be used here merely by the substitution $\mu_{0} \rightarrow \mu=\mu_{\mathrm{r}} \mu_{0}$.

\section{Total Mass}

The sum of the core and winding masses is simply

$$
\mathrm{M}=\rho_{\mathrm{c}} \mathrm{v}_{\mathrm{c}}+\rho_{\mathrm{w}} \mathrm{v}_{\mathrm{w}}
$$

in terms of the indicated densities and volumes. In the present geometry, the core and winding volumes are given by simple formulas:

$$
\begin{gathered}
v_{\mathrm{w}}=\pi^{3} \mathrm{C} \delta \mathrm{r}_{1}^{1 / 2} \\
\mathrm{v}_{\mathrm{C}}=2 \pi^{2} \mathrm{r}_{1} \mathrm{r}_{2}^{2} .
\end{gathered}
$$

As shown in Appendix A, $r_{1}$ is a function of $r_{2}$, given by Eq. (A4), with the substitution $\mu_{0} \rightarrow \mu=\mu_{r} \mu_{0}$ in Eq. (A3). From the explicit expression

$$
v_{c}=\frac{\pi^{2}}{2}\left[C+\left(C^{2}+4 r_{2}^{3}\right)^{1 / 2}\right]^{2}
$$

it is clear that $v_{c}$ is a monotonic function of $r_{2}$. Instead of trying to minimize $M$ directly by differentiating Eq. (9) with respect to $r_{2}$ (which yields a high order equation in $r_{2}$ ), let us assume that there is no mass advantage in 
operating the core at a B-field less than the maximum allowed $\mathrm{B}_{\mathrm{p} \text {, max }}$. Any lingering doubts about this assumption will be removed finally by showing that the minimum total mass is a monotonic function of $\mathrm{B}_{\mathrm{p} \text {,max }}$. Proceeding in the meantime,

$$
v_{c}=\frac{\pi^{2}}{2}\left[C+\left(C^{2}+4 r_{2}^{3}\right)^{1 / 2}\right]^{2}=\mu L\left(I_{p, \text { max }} / B_{p, \text { max }}\right)^{2},
$$

which determines a value for $\mathrm{r}_{2}$ denoted by $\mathrm{r}_{2}{ }^{* *}$. We easily find that

$$
\mathrm{r}_{2}^{* *}=\left(\frac{\mathrm{L}}{2 \pi^{2}}\right)^{1 / 3}\left(\frac{\mathrm{I}_{\mathrm{p}, \max }}{\mathrm{B}_{\mathrm{p}, \max }}\right)^{1 / 3}\left[\mu\left(\frac{\mathrm{I}_{\mathrm{p}, \max }}{\mathrm{B}_{\mathrm{p}, \max }}\right)-\delta\right]^{1 / 3},
$$

and

$$
\mathrm{r}_{1}^{* *}=\mu\left(\frac{\mathrm{L}}{2 \pi^{2}}\right)\left(\frac{\mathrm{I}_{\mathrm{p}, \max }}{\mathrm{B}_{\mathrm{p}, \max }}\right)^{2} /\left(\mathrm{r}_{2}^{* *}\right)^{2}
$$

The solution given by Eq. (14) exists, if and only if

$$
\delta<\mu \mathrm{I}_{\mathrm{p}, \max } / \mathrm{B}_{\mathrm{p}, \max }
$$

This is a strong restriction relating wire size, or spacing, to permeability and specified parameters. If for some reason this inequality is not satisfied, then a solution for $\mathrm{r}_{2}{ }^{* *}$ does not exist, unless the $\mathrm{B}_{\mathrm{p} \text {, max }}$ is lowered. In other words, the core will operate at a lower than allowed maximum B-field. But as assumed above and proved later, there is no manifest mass or size advantage to such a mode.

\section{A Lower Bound on $\mu$}

The contents of Eq. (16) can be developed further by assuming that the conductor size is limited by a specified maximum rms current density $\mathrm{J}_{\max }$ such that

$$
\pi(\mathrm{w} / 2)^{2} \mathrm{~J}_{\max }=\mathrm{I}_{\mathrm{rms}, \max }=\frac{1}{\sqrt{2}} \mathrm{I}_{\mathrm{p}, \max },
$$

where $\mathrm{w}$ is the diameter of the conductor. Eq. (17) can be easily solved for $\mathrm{w}$. Let us introduce a number $\mathrm{t}$ to account for additional wire separation due to insulation thickness, or possibly just spacing. Then

$$
\delta=w+2 t=\left(\frac{2^{3 / 2}}{\pi}\right)^{1 / 2}\left(\frac{I_{p, \max }}{J_{\max }}\right)^{1 / 2}+2 t
$$

Using the value of $\delta$ from Eq. (18), Eq. (16) can be written in the form

$$
\mu>\left(\frac{B_{p, \max }}{I_{p, \max }}\right)\left[\left(\frac{2^{3 / 2}}{\pi}\right)^{1 / 2}\left(\frac{I_{p, \max }}{J_{\max }}\right)^{1 / 2}+2 t\right] .
$$

Hence increased wire spacing or reduced current density requires a higher $\mu$, thus increasing core volume.

\section{Design Parameters Determined by the Dimensional Scaling Ratio $S$}

Physical realizability requires that the dimensional scaling ratio $S$, defined by $S \equiv r_{2} / r_{1}$, be restricted to a range narrower than the maximum possible $0<\mathrm{S}<1$. Thus even $\mathrm{S}=0.5$ makes for an overly "fat" torus and so such cores are not standard products. $\mathrm{S}$ is a very convenient and physically meaningful degree of freedom and indeed fixes the values of $r_{1}, r_{2}, N$ and $\mu$. Substitutions lead to the following results: 
Using $r_{1}=r_{2} / S$ in Eq. (15) gives

$$
\mathrm{r}_{2}^{* *}=\left[\mu \mathrm{S}\left(\frac{\mathrm{L}}{2 \pi^{2}}\right)\left(\frac{\mathrm{I}_{\mathrm{p}, \max }}{\mathrm{B}_{\mathrm{p}, \max }}\right)^{2}\right]^{1 / 3}
$$

and hence

$$
\mathrm{r}_{1}^{* *}=\mathrm{r}_{2}^{* *} / \mathrm{S}=\left[\mu \mathrm{S}^{-2}\left(\frac{\mathrm{L}}{2 \pi^{2}}\right)\left(\frac{\mathrm{I}_{\mathrm{p}, \max }}{\mathrm{B}_{\mathrm{p}, \max }}\right)^{2}\right]^{1 / 3}
$$

The $\mu$ is found by eliminating $r_{2}{ }^{* *}$ between Eqs. (14), (20), and then using Eq. (18) to eliminate $\delta$. The result is

$$
\mu=\left(\frac{1}{1-S}\right)\left(\frac{B_{p, \max }}{I_{p, \text { max }}}\right) \delta=\left(\frac{1}{1-S}\right)\left(\frac{B_{p, \max }}{I_{p, \max }}\right)\left[\left(\frac{2^{3 / 2}}{\pi}\right)^{1 / 2}\left(\frac{I_{p, \max }}{J_{\max }}\right)^{1 / 2}+2 t\right] .
$$

This explicit value for $\mu$ can be substituted in Eqs. (20) and (21), to give

$$
\mathrm{r}_{2}^{* *}=\left[\left(\frac{\mathrm{L}}{2 \pi^{2}}\right)\left(\frac{\mathrm{S}}{1-\mathrm{S}}\right)\left(\frac{\mathrm{I}_{\mathrm{p}, \max }}{\mathrm{B}_{\mathrm{p}, \max }}\right) \delta\right]^{1 / 3}
$$

and

$$
\mathrm{r}_{1}^{* *}=\mathrm{S}^{-1} \mathrm{r}_{2}^{* *}=\left[\left(\frac{\mathrm{L}}{2 \pi^{2}}\right)\left(\frac{\mathrm{S}^{-2}}{1-\mathrm{S}}\right)\left(\frac{\mathrm{I}_{\mathrm{p}, \max }}{\mathrm{B}_{\mathrm{p}, \max }}\right) \delta\right]^{1 / 3}
$$

where $\delta$ is given by Eq. (18).

The number of turns $\mathrm{N}$ can be found from the geometrical formula $\mathrm{N}=2 \pi\left(\mathrm{r}_{1}-\mathrm{r}_{2}\right) / \delta$, or from several other formulas above, such as Eq. (5). The result is

$$
\mathrm{N}=\left[4 \pi \mathrm{L}\left(\mathrm{S}^{-1}-1\right)^{2}\left(\frac{\mathrm{I}_{\mathrm{p}, \max }}{\mathrm{B}_{\mathrm{p}, \max }}\right)\right]^{1 / 3} /\left[\left(\frac{2^{3 / 2}}{\pi}\right)^{1 / 2}\left(\frac{\mathrm{I}_{\mathrm{p}, \max }}{\mathrm{J}_{\max }}\right)^{1 / 2}+2 \mathrm{t}\right]^{2 / 3} .
$$

Finally, the core and winding volumes can be written as explicit functions of the sole degree of freedom, which was taken to be S. Eqs. (13) and (22) combine to give

$$
v_{c}=\frac{L}{(1-S)}\left(\frac{I_{p, \max }}{B_{p, \max }}\right) \delta .
$$

By a somewhat tedious calculation from Eqs. (10), (A3) and (24), the winding volume is found to be

$$
v_{w}=\left[\left(S^{-1}-1\right) \pi^{5}\left(\frac{L}{2}\right)^{2} \delta^{5}\left(\frac{I_{p, \max }}{B_{p, \max }}\right)^{2}\right]^{1 / 3}
$$

The ratio of these volumes, namely

$$
\frac{v_{c}}{v_{w}}=\left[\frac{4 S L\left(I_{p, \max } / B_{p, \max }\right)}{(1-S)^{4} \pi^{5} \delta^{2}}\right]^{1 / 3}
$$


is of interest in cases where it may be admissible to reduce core volume by going to a multi-layer winding. In the single-layer case to which Eq. (28) applies, there is a tendency for the core volume to considerably exceed the winding volume until low values of $\mathrm{S}$ are reached.

\section{Minimum Mass}

From the facts that $v_{w} \rightarrow \infty, v_{c} \rightarrow$ const. as $S \rightarrow 0$ and $v_{w} \rightarrow 0, v_{c} \rightarrow \infty$ as $S \rightarrow 1$, it follows that the total mass $M$, as given by Eq. (9), has a minimum value $M_{\min }$ at some $S=S^{*}$. In spite of the complicated dependence on S in Eqs. (26) and (27), it turns out that an algebraic solution of this minimum problem is straight forward by the usual differentiation technique. To this end, let $\mathrm{M}$ be written in the form

$$
\mathrm{M}=\mathrm{a}_{\mathrm{c}}(1-\mathrm{S})^{-1}+\mathrm{a}_{\mathrm{w}}\left(\mathrm{S}^{-1}-1\right)^{1 / 3},
$$

where the constants $\mathrm{a}_{\mathrm{c}}$ and $\mathrm{a}_{\mathrm{w}}$ are defined by

$$
a_{c} \equiv \rho_{c} L\left(\frac{I_{p, \max }}{B_{p, \max }}\right) \delta
$$

and

$$
\mathrm{a}_{\mathrm{w}} \equiv \rho_{\mathrm{w}}\left[\left(\pi^{5} / 4\right) \mathrm{L}^{2} \delta^{5}\left(\mathrm{I}_{\mathrm{p}, \max } / \mathrm{B}_{\mathrm{p}, \max }\right)^{2}\right]^{1 / 3}
$$

Setting $\mathrm{dM} / \mathrm{dS}=0$, gives the simple solution

$$
\mathrm{S} *=\left[\left(3 \mathrm{a}_{\mathrm{c}} / \mathrm{a}_{\mathrm{w}}\right)^{3 / 4}+1\right]^{-1}
$$

which when substituted back into Eq. (29) gives the minimum mass

$$
\mathrm{M}_{\min }=\mathrm{a}_{\mathrm{c}}\left[1+4\left(\frac{\mathrm{a}_{\mathrm{w}}}{3 \mathrm{a}_{\mathrm{c}}}\right)^{3 / 4}\right]
$$

At this point, the validity of the assumption that there is no mass advantage in operating the core at a B-field less than the maximum allowed $B_{p, \text { max }}$ is proved. Inspection of Eq. (33), after substitution of $a_{c}$ and $a_{w}$ from Eqs. (30) and (31), shows that $\mathrm{M}_{\min }$ is a monotonically decreasing function of $\mathrm{B}_{\mathrm{p} \text {, max }}$.

An illustrative plot of $\mathrm{M}(\mathrm{S})$ is provided in the next section. An analysis of the sensitivities present in $\mathrm{S}^{*}$ and Mmin will not be attempted here. Suffice it to say that for often seen cases of single-layer windings, the core mass considerably predominates and $\mathrm{S}^{*}$ may then be impractical to realize. However, an off-minimum mass design is not likely to incur a serious mass penalty, because in magnetics work, such minima tend not to be very sharp.

\section{Sample Plots and Values}

To generate illustrative plots, let us assume $1 \mathrm{mH}$ inductor built on a class of quasilinear core materials, all having the same $\mathrm{Bp}, \max \approx 0.6 \mathrm{~T}$, but variable relative permeabilities $\mu \mathrm{r}$. This approximately applies to the MPP family of cores. The peak current Ip, max is taken to be $10 \mathrm{~A}$. The wire diameter is picked to be such that a sinusoidal current of 10 A peak gives a maximum rms current density Jrms, max $=3 \times 106 \mathrm{~A} / \mathrm{m} 2(300 \mathrm{~A} / \mathrm{cm} 2)$. Assuming the insulation thickness to be negligible $(\mathrm{t}=0), \delta=1.73 \times 103 \mathrm{~m}$. The radii, the turns, the relative permeability and the volumes are plotted in Fig. 2. Commercial MPP cores with S roughly in the range 0.15 to 0.35 are very common and stacking can simulate a higher S. Overall diameters less than $8 \mathrm{~cm}$ should be feasible; at $\mathrm{S} \approx 0.3$, for example, the overall diameter is only slightly above the minimum possible. The turns then would be roughly 72 and the relative permeability would be around 118. It is also clear that in the above range of $\mathrm{S}$, the total volume is not very sensitive to $\mathrm{S}$. However, most of the volume is in the core, being $41.2 \mathrm{~cm}^{3}$ for the core and only $9.18 \mathrm{~cm}^{3}$ for the winding. Assuming copper wire on an MPP core $\left(\rho_{\mathrm{Cu}}=8.89 \mathrm{~g} / \mathrm{cm}^{3}, \rho_{\mathrm{MPP}} \approx 8.41 \mathrm{~g} / \mathrm{cm}^{3}\right)$, the total mass is about $428 \mathrm{~g}$. This mass can be lowered slightly by going to the minimum mass point, which is $395 \mathrm{~g}$ at $\mathrm{S}=0.135$ for the specified design parameters. But this gains little, at the cost of a considerably larger overall diameter and increased turns. The mass curve in Fig. 3 is rather flat in roughly the $0.1<\mathrm{S}<0.4$ range, but the overall 
size and required turns have a much larger relative variation (Fig. 2). Hence this example shows that, at least for the given specifications, a region of $\mathrm{S}$ can be found where both the size and mass have a low sensitivity to $\mathrm{S}$ and the turns and permeability have physically practical values.

\section{Illustration: An MPP Inductor at $250 \mathrm{C}$}

Magnetically quasi-linear molybdenum permalloy powder (MPP) cores are an industry standard for "workhorse" inductor applications up to about $300 \mathrm{kHz}$. Cores are available in various permeability grades and sizes up to several inches OD. Their losses are sufficiently low such that inductors with Q-factors in the hundreds can be produced. Although their finishes are often rated to $200 \mathrm{C}$, high temperature core loss data is usually not available in the vendor catalogs. The following is an example of MPP core selection to make an unsophisticated $1 \mathrm{mH}, 10 \mathrm{~A}$ peak rated inductor that is capable of operating at $250 \mathrm{C}$.

The type 55090 temperature stabilized MPP core has cross-section $\mathrm{A}=1.34 \times 10^{-4} \mathrm{~m}^{2}$, a mean path $\bar{\ell}=0.116 \mathrm{~m}$ and a specified permeability $\mu_{\mathrm{r}}=60$. Hence its core volume is $1.55 \times 10^{-5} \mathrm{~m}^{3}$. Admittedly not conservative, but a peak allowed B-field of $0.6 \mathrm{~T}$ was picked for this material. According to Eq. (4), the minimum allowed core volume for this case is $v_{\min }=2.09 \times 10^{-5} \mathrm{~m}^{3}$. Hence a single 55090 core cannot be used to make up the desired inductor, but 2 such cores would have a volume of $3.10 \times 10^{-5} \mathrm{~m}^{3}$, which is more than sufficient. Going to the next higher permeability grade of 125 in order to reduce the number of turns (cf, Eq. (2)) requires double the core volume and suitable cores of roughly the same $\bar{\ell}$ were not on hand. Suitable lower permeability cores were not available either. Hence it was decided to stack two of the 55090 cores. From Eq. (2), the number of turns N is then 76. The 18 AWG, Teflon insulated copper wire that was used for the winding is normally rated at only $4.34 \mathrm{~A} \mathrm{rms}$, but even that size is too thick for a single-layer winding on this core. Nevertheless, the wire is high temperature capable and demonstration of low winding loss was not an objective.

Measurements of the inductance versus temperature up to $250 \mathrm{C}$ and at several selected values of peak current up to $10 \mathrm{~A}$ are presented in Fig. 4. This data was obtained from measurements of current in the 76 turns and of the voltage induced in a 10-turn sense winding to eliminate effects of resistive voltage drops. As may be expected, the rated effective permeability of 60 is accurate only at low currents and decreases with onset of magnetic saturation effects at the $10 \mathrm{~A}$ design current. For the selected stacked core and winding and a $\mu \mathrm{r}$ of 60 , at $10 \mathrm{~A}$ peak the B-field is $0.49 \mathrm{~T}$.

\section{Discussion and Conclusions}

Assuming for simplicity a uniform B-field over the core cross-section, AC power inductor designs having a fixed inductance $(\mathrm{L})$ that fully utilize a specified core material at a specified peak current have a core volume that is proportional to the magnetic permeability ( $\mu \mathrm{r})$ of the material, but is independent of the shape scaling ratio. This somewhat counter intuitive result can be understood from energy storage considerations, together with the fact that the core material is operating at a fixed maximum allowed peak B-field (Bp, max). The Bp, max is limited by the onset of magnetic saturation and by the need to control core loss at high frequencies. As the Bp, max is reduced, the minimum core volume ( $v_{c}$, min $)$ grows rapidly (see Eq. (4)). At fixed core volume and ratings, the core loss is fixed and the remaining degrees of freedom are conveniently taken to be the dimensional scaling ratios, whose variation affects the relative permeability $\left(\mu_{\mathrm{r}}\right)$, the absolute dimensions, the number of turns $(\mathrm{N})$ and the winding losses. For a torus-shaped core, there is only 1 degree of freedom, which can be taken to be the ratio $(0<S<1)$ of the radii. If lower losses are desired, one can always pick a lower $\mathrm{B}_{\mathrm{p}, \max }$, but at the cost of increased core volume and mass.

The reduction of core volume, by say reducing $\mu_{\mathrm{r}}$, is limited by the resulting increase in the number of turns per mean circumference of the core $(\mathrm{N} / \bar{\ell})$. If this number is greater than the reciprocal of the wire diameter, then a single-layer winding is clearly impossible; indeed, the periphery of the core window area can be significantly less

than $\bar{\ell}$. The model developed here takes that into account, for a simple calculation shows that $\mathrm{N} / \bar{\ell}=(1-\mathrm{S}) / \delta$. Therefore as $S \rightarrow 0$, the shape of the torus becomes a thin ring of increasing major radius, which finally leads to an increasing winding volume. At least in the worked out example, the overall diameter and mass minima are sufficiently flat to admit a compromise without severe penalties in either mass or size. 
Single-layer windings are desirable to facilitate heat extraction from a magnetic core at high temperatures, or to minimize capacitive effects at high frequencies. An unsophisticated example, with data to $250 \mathrm{C}$, is provided to show that a $1 \mathrm{mH}$, high temperature inductor can be based on a readily available MPP core.

Especially at high temperatures, and also at high frequencies, the air-core inductor can be a strong candidate, for it has no magnetic material limitations. The case of a single-layer winding on a torus is outlined in Appendix A. There it is shown in a simple model that for a given inductance and wire spacing, the major radius of the torus is determined as a function of the minor radius, leaving again only 1 degree of freedom. The permeability is now fixed, but there is no restriction on the peak B-field. The wire volume can again be evaluated explicitly in this case and has a minimum at a certain value of the dimensional scaling ratio. Numbers are given for a $1 \mathrm{mH}, 10 \mathrm{~A}$ rated inductor, showing it to be considerably larger and heavier than a similarly rated inductor based on an MPP core. However, an air-core power inductor is a better candidate for a multi layer winding design, since it can tolerate much higher temperature rises. Hence under extreme environmental conditions, the air-core inductor may have an advantage sufficient to warrant further investigation. 


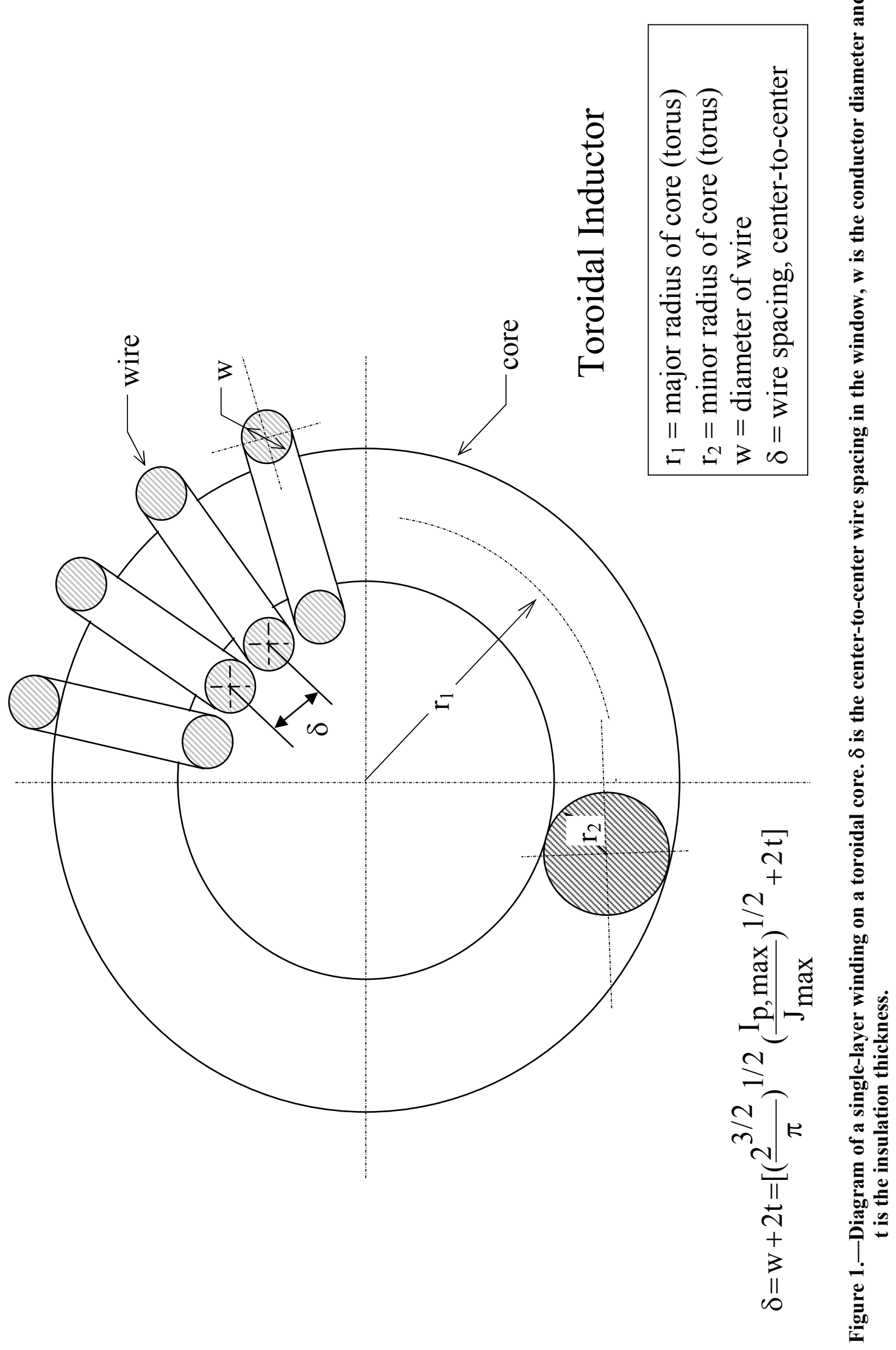




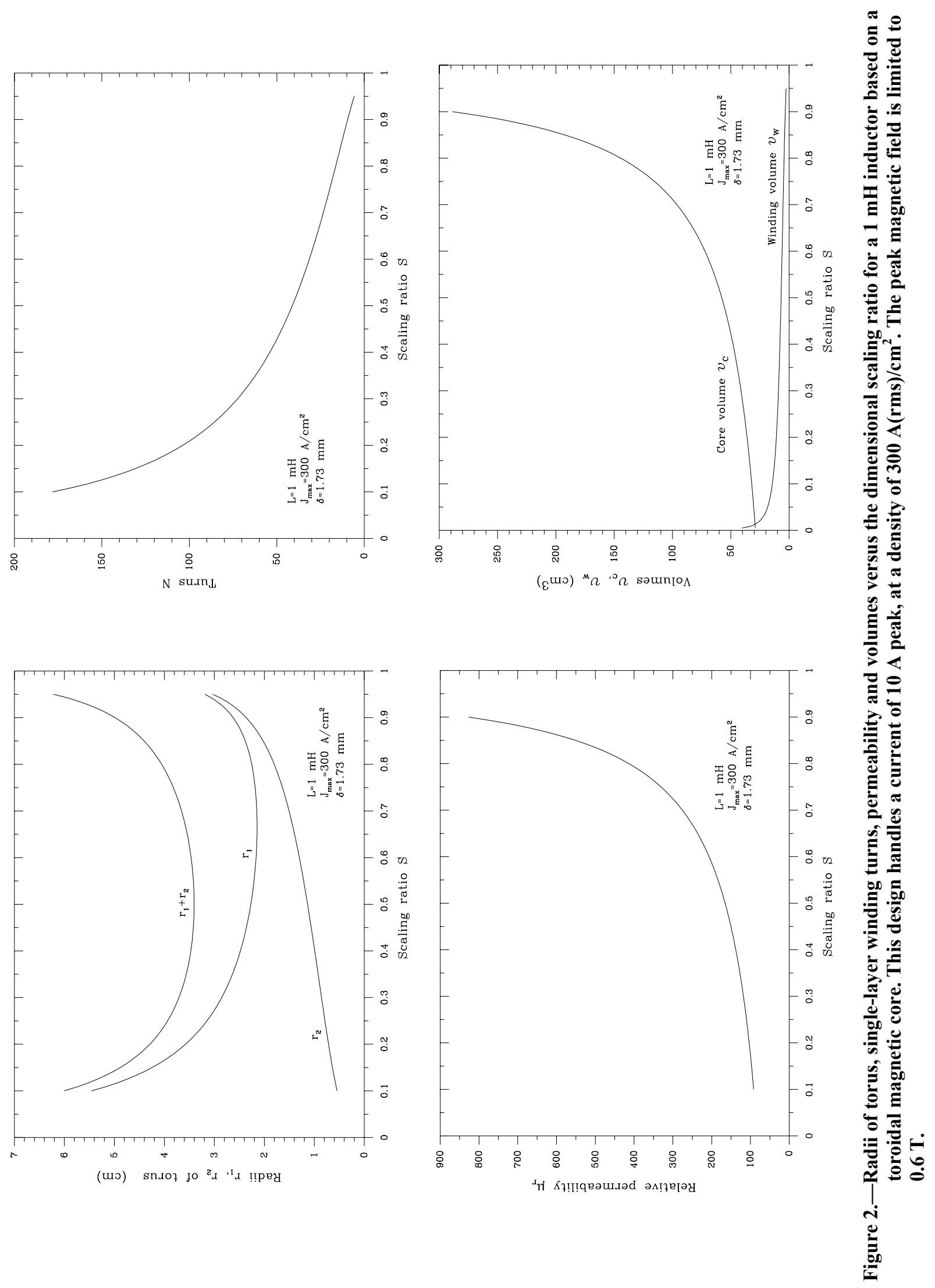

NASA/CR-2005-213354 


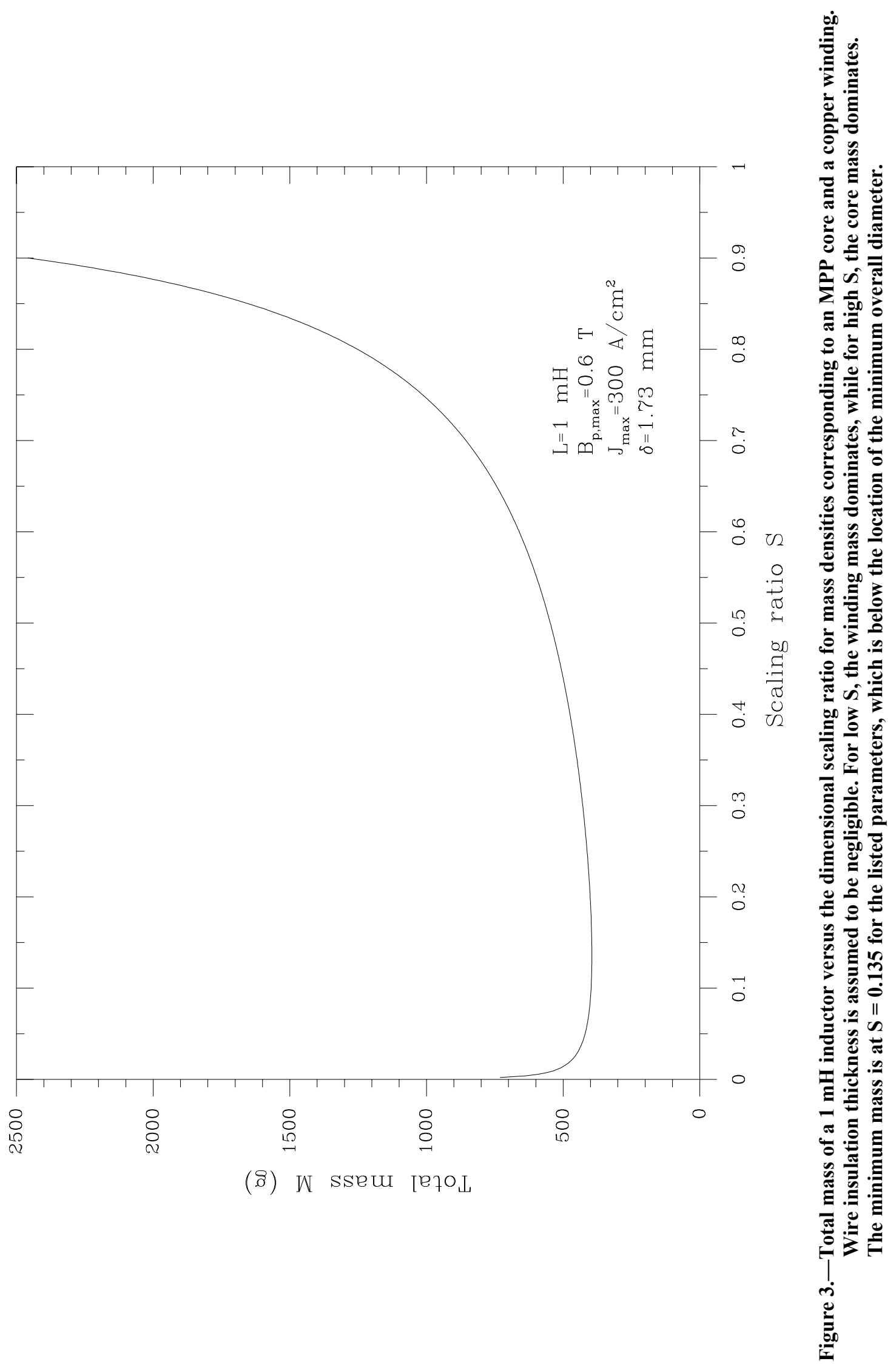

NASA/CR—2005-213354 


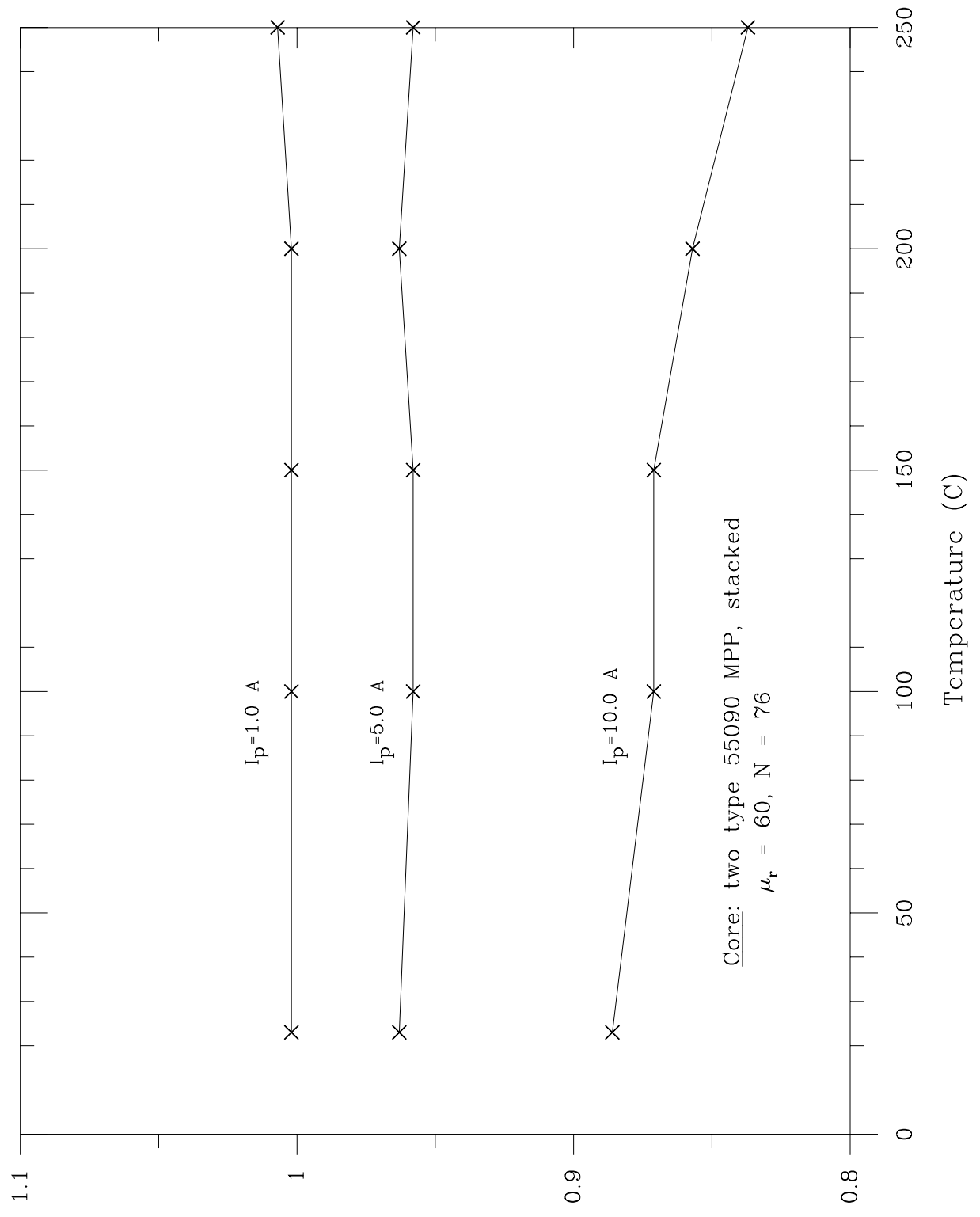

(iu) I әəчеғопри

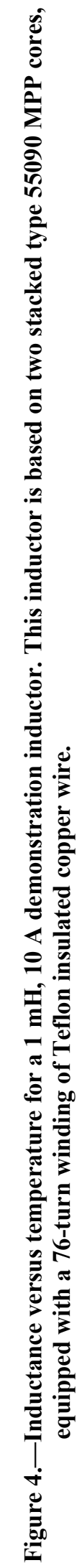




\section{Appendix A}

\section{The Toroidal Air-Core Inductor}

In the uniform B-field approximation, the toroidal air/vacuum core case is explicitly soluble and therefore valuable for first-cut design guidance as well as comparison to cases using magnetic cores. To minimize free parameters, the geometry is assumed to be a torus having a major radius $r_{1}$ and a minor radius $r_{2}$. Then $r_{2}<r_{1}$. Again for simplicity, the winding distribution is assumed to be a single layer of $\mathrm{N}$ turns, with a wire center-to-center spacing $\delta$ around the periphery of the window area of the torus. Such a winding is suitable at high temperatures and currents. The $\delta$ can be no less than the wire diameter, including any insulation, and is assumed to be given. The further assumption that $\delta<<\left(r_{1}-r_{2}\right)$ makes the formula $N=2 \pi\left(r_{1}-r_{2}\right) / \delta$ accurate. For this geometry, $\bar{\ell}=2 \pi r_{1}$ and $\mathrm{A}=\pi \mathrm{r}_{2}^{2}$. And as before, the inductance $\mathrm{L}$ is assumed to be specified.

Inspection shows that there exists a relation between $r_{1}, r_{2}$ and the specified parameters. Moreover, there is only one degree of freedom in the problem, which can be taken to be $r_{2}$. This relation turns out to be easily derived and solved for $r_{1}$ as a function of $r_{2}$ and the parameters. To this end, the first step is to find $\mathrm{N}$ from Eq. (2) in the present geometry:

$$
\mathrm{N}=\left(2 \mathrm{r}_{1} \mathrm{~L} / \mu_{0}\right)^{1 / 2} / \mathrm{r}_{2}
$$

Next, $N$ can be eliminated by using $N=2 \pi\left(r_{1}-r_{2}\right) / \delta$ to obtain the desired relation. This relation can then be put into the form

$$
\left(\mathrm{r}_{1}^{1 / 2}-\frac{\mathrm{r}_{2}}{\mathrm{r}_{1}^{1 / 2}}\right) \mathrm{r}_{2}=\mathrm{C},
$$

where the constant $\mathrm{C}$ is defined by

$$
\mathrm{C} \equiv\left(\frac{\delta}{\pi}\right)\left(\frac{\mathrm{L}}{2 \mu_{0}}\right)^{1 / 2}
$$

Since $C>0$, it follows immediately from Eq. (A2) that $r_{1}>r_{2}$ is satisfied for positive $r_{1}$ and $r_{2}$.

Equation (A2) is a quadratic equation in $\mathrm{r}_{1}{ }^{1 / 2}$, whose only positive root is

$$
\mathrm{r}_{1}^{1 / 2}=\left[\mathrm{C}+\left(\mathrm{C}^{2}+4 \mathrm{r}_{2}^{3}\right)^{1 / 2}\right] /\left(2 \mathrm{r}_{2}\right)
$$

Instead of $r_{2}$, it is more convenient to choose the scaling ratio $S \equiv r_{2} / r_{1}$, where $0<S<1$, as the 'degree of freedom'. Expressed in the S-parameterization,

$$
\begin{gathered}
\mathrm{r}_{1}=\left[\frac{\mathrm{C}}{\mathrm{S}(1-\mathrm{S})}\right]^{2 / 3}, \\
\mathrm{r}_{2}=\mathrm{Sr}_{1}=\left[\frac{\mathrm{CS}^{1 / 2}}{(1-\mathrm{S})}\right]^{2 / 3} .
\end{gathered}
$$

The minimum value of $r_{1}$ is at $S=1 / 2$, where 


$$
\mathrm{r}_{2}^{*} \equiv \mathrm{r}_{2 \mid \mathrm{S}=1 / 2}=2^{1 / 3} \mathrm{C}^{2 / 3}
$$

and at which point $r_{1}$ has the value

$$
\left(\mathrm{r}_{1}\right)_{\min }=\mathrm{r}_{1 \mid \mathrm{S}=1 / 2}=2^{4 / 3} \mathrm{C}^{2 / 3}=2 \mathrm{r}_{2}^{*}
$$

The number of turns $\mathrm{N}$ is needed in order to implement the design and to compute the winding volume $v_{\mathrm{w}}$. However, this number is already known from Eq. (A1):

$$
\mathrm{N}=\left(2 \mathrm{~L} / \mu_{0}\right)^{1 / 2} \mathrm{r}_{1}^{1 / 2} / \mathrm{r}_{2}=\left[\left(\frac{\pi}{\delta}\right)\left(\frac{4 \mathrm{~L}}{\mu_{0}}\right)\left(\frac{1-\mathrm{S}}{\mathrm{S}^{2}}\right)\right]^{1 / 3},
$$

where $\mathrm{r}_{1}^{1 / 2}$ is given by Eq. (A4). For fixed $\delta$ and $\mathrm{L}, \mathrm{N}$ is a monotonically decreasing function of $\mathrm{S}$, or of $\mathrm{r}_{2}$.

The winding volume $v_{\mathrm{w}}$ is likewise a simple computation, if one ignores helicity of the winding and treats each turn as a circle of radius $r_{2}$. The result is

$$
\mathrm{v}_{\mathrm{w}}=\frac{\pi^{2}}{2} \delta^{2} \mathrm{r}_{2} \mathrm{~N}
$$

Then using Eqs. (A9) and (A3), Eq. (A10) becomes

$$
\mathrm{v}_{\mathrm{w}}=\pi^{3} \mathrm{C} \delta \mathrm{r}_{1}^{1 / 2}=\left[\pi^{5} \delta^{7}\left(\frac{\mathrm{L}}{2 \mu_{0}}\right)^{2} \frac{1}{\mathrm{~S}(1-\mathrm{S})}\right]^{1 / 3}
$$

where $r_{1}^{1 / 2}$ is again given by Eq. (A4). A noteworthy part of the above result is that $v_{w}$ is within a constant, the same function of $r_{2}$, or of $S$, as is $r_{1}^{1 / 2}$ and hence also has a minimum at $r_{2}{ }^{*}$ given by Eq. (A7), or equivalently, at $S=$ $1 / 2$. Therefore

$$
v_{\mathrm{w}, \min }=2^{2 / 3} \pi^{3} \delta \mathrm{C}^{4 / 3}=\left[\pi^{5} \delta^{7}\left(\frac{\mathrm{L}}{\mu_{0}}\right)^{2}\right]^{1 / 3}
$$

Eq. (18) connects this to current, showing that $v_{w, \min } \propto\left(I_{p, \max } / J_{\max }\right)^{7 / 6}$. This variation of $v_{w, \min }$ with $J_{\max }$ is illustrated in Fig. (A1) for $1 \mathrm{mH}$ inductor. Also included in Fig. (A1) are illustrative plots, for a fixed $\mathrm{J}_{\max }$, of the sizes and extremum properties developed above. Although the S-values for minimum winding volume and minimum overall diameter are different, these minima are not very sharp.

To appreciate the cost of going from a magnetic material to the air core, let us evaluate the size of a $1 \mathrm{mH}$, minimum mass $(\mathrm{S}=0.5)$ air core inductor, designed to carry $10 \mathrm{~A}$ peak, at an rms current density of $300 \mathrm{~A} / \mathrm{cm}^{2}$. The wire diameter $\delta$ is then $1.73 \mathrm{~mm}$ (about $14 \mathrm{AWG}$, if not insulated) and we need 226 turns. In this case, $\mathrm{r}_{2}=6.23 \mathrm{~cm}$ and $r_{1}=12.5 \mathrm{~cm}$, giving an overall diameter of $37.4 \mathrm{~cm}$ (14.7 inches). Its winding volume $v_{\mathrm{w}}$ is $209 \mathrm{~cm}^{3}$, making for a copper mass of $1.85 \mathrm{~kg}$. Thus this single-layer wound, air-core inductor is about 5 times larger in overall diameter and about 4.3 times heavier than the single-layer wound MPP-core inductor described previously. However, a multilayer design should reduce the size and mass of the air-core inductor and such would be feasible even at high temperature. Hence the more complicated, multi-layer wound, air-core model may well be worth investigating. 


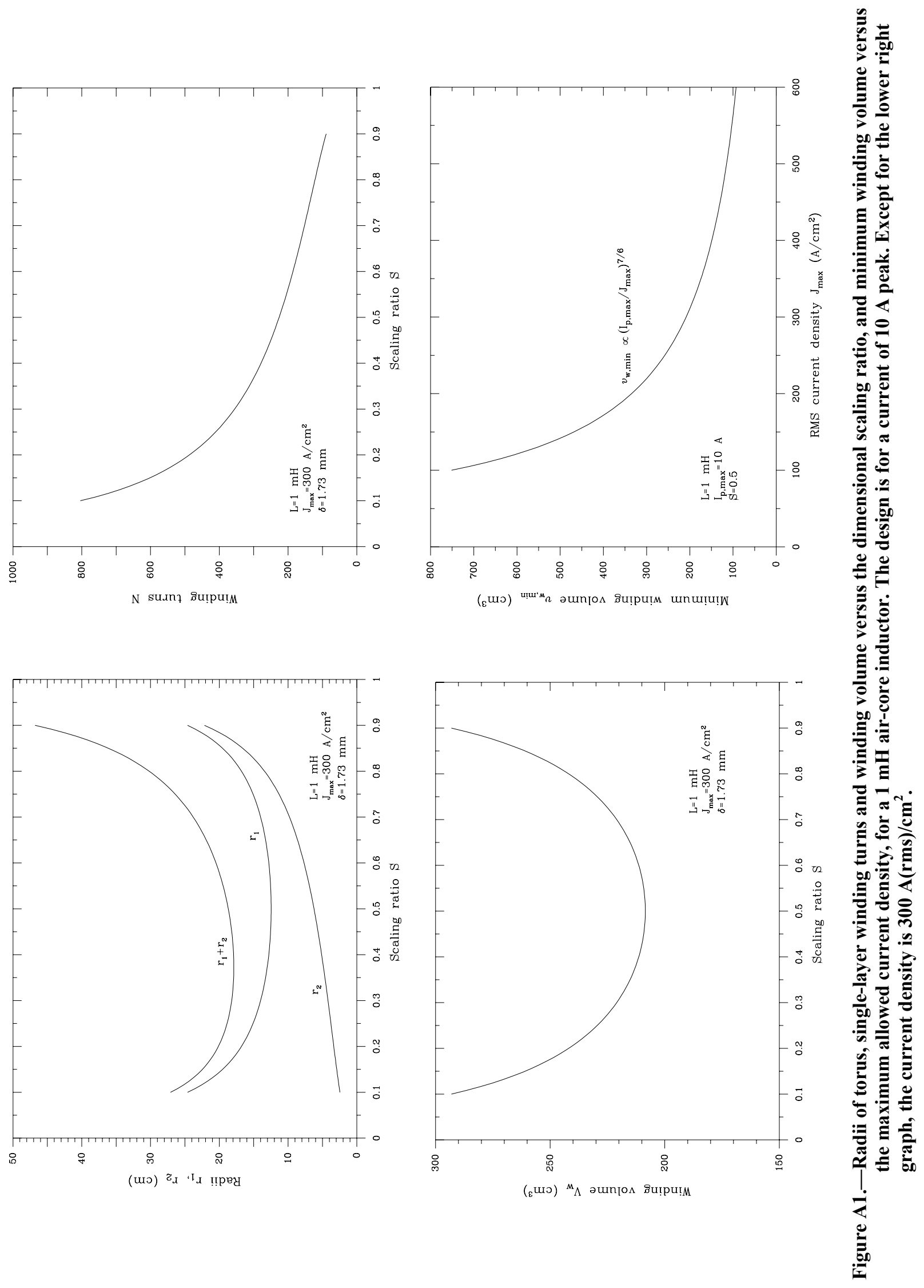

NASA/CR-2005-213354 


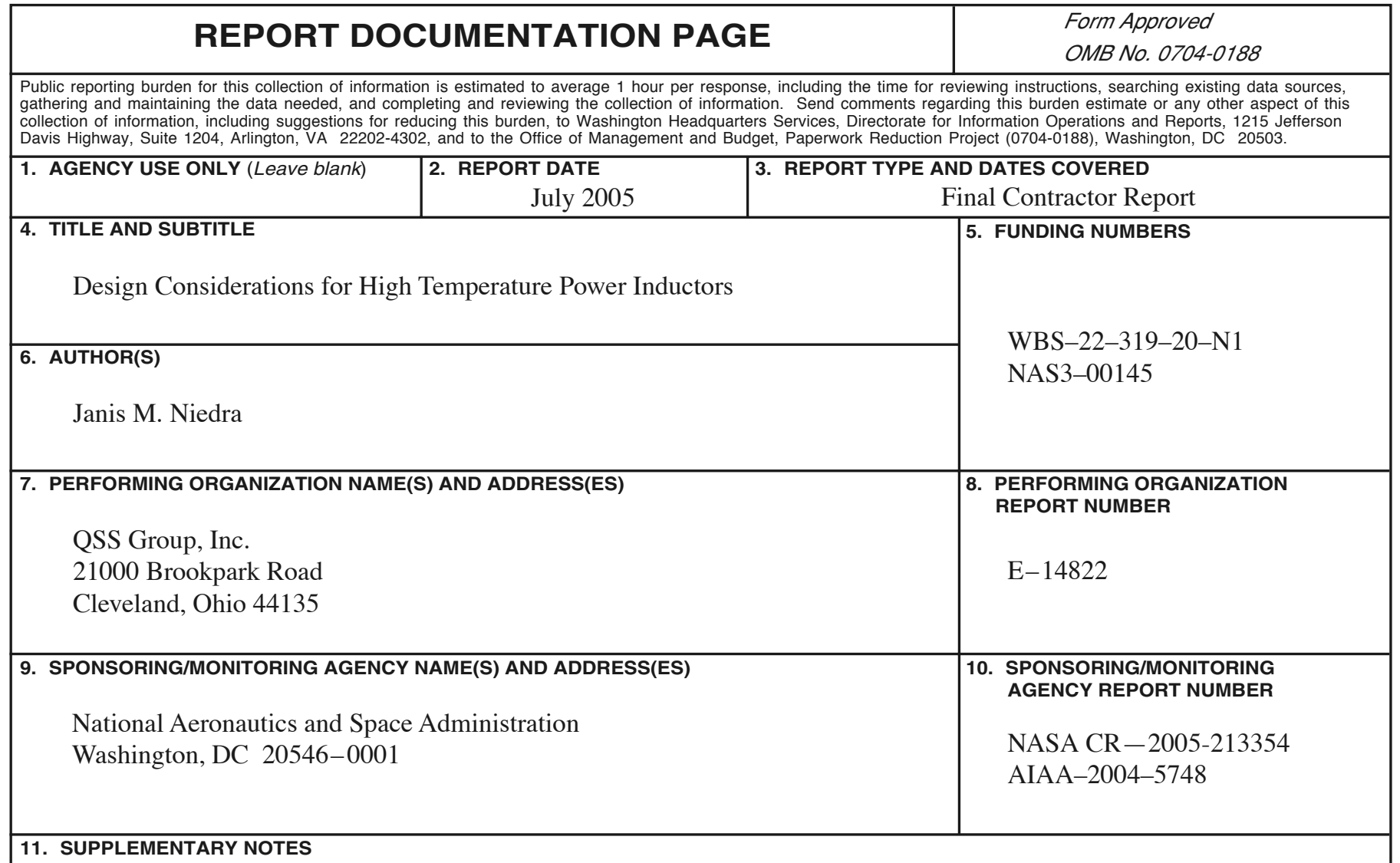

Prepared for the Second International Energy Conversion Engineering Conference sponsored by the American Institute of Aeronautics and Astronautics, Providence, Rhode Island, August 16-19, 2004. Project Manager, Thomas P. Burke, Systems Engineering Division, NASA Glenn Research Center, organization code DE, 216-433-6172.

12a. DISTRIBUTION/AVAILABILITY STATEMENT

12b. DISTRIBUTION CODE

Unclassified - Unlimited

Subject Category: 33

Distribution: Nonstandard

Available electronically at http://gltrs.grc.nasa.gov

This publication is available from the NASA Center for AeroSpace Information, 301-621-0390.

13. ABSTRACT (Maximum 200 words)

A uniform B-field approximation model is used to develop design formulas for single-layer wound, toroidal core, ac power inductors that must handle a specified current. Such a geometry is well suited for high temperature, high frequency inductors, where removal of heat from the core becomes critical. Explicit expressions are derived for core radii, core and winding volumes, winding turns and core permeability as functions of a dimensional scaling ratio (S). A limit on the maximum allowed core B-field leads to the result that the minimum core volume is proportional to the permeability, which has a lower bound. Plots versus $\mathrm{S}$ are provided for a specific case, to show that good designs can be picked in the overlap regions around the minima in mass and overall size, where the mass and size are relatively flat. Data to $250{ }^{\circ} \mathrm{C}$ are presented for an MPP core based inductor to show that a quasi-linear, high temperature inductor can be constructed with available materials. A similar development is applied to a toroidal air-core geometry, showing that for the same ratings, such an inductor is considerably bigger and more massive, at least in the single-layer version.

14. SUBJECT TERMS

High temperature inductors; Magnetic cores; Toroidal coils; Permalloys

\begin{tabular}{|c|c|c|c|}
\hline $\begin{array}{c}\text { 17. SECURITY CLASSIFICATION } \\
\text { OF REPORT } \\
\text { Unclassified }\end{array}$ & $\begin{array}{c}\text { 18. SECURITY CLASSIFICATION } \\
\text { OF THIS PAGE } \\
\text { Unclassified }\end{array}$ & $\begin{array}{c}\text { 19. SECURITY CLASSIFICATION } \\
\text { OF ABSTRACT } \\
\text { Unclassified }\end{array}$ \\
\hline
\end{tabular}

NSN 7540-01-280-5500

Standard Form 298 (Rev. 2-89)

Prescribed by ANSI Std. Z39-18 298-102 

